\title{
Dimensionality of the California Preschool Social Competency Scale
}

\author{
David L. Flint, Thomas L. Hick, Mary D. Horan, \\ David J. Irvine, and Susan E. Kukuk \\ The University of the State of New York \\ The State Education Department
}

The structure and construct validity of the California Preschool Social Competency Scale as used with disadvantaged children $(N=1,723)$ in New York State was investigated through factor analysis. Five factors were extracted and interpreted as (1) Considerateness; (2) Extraversion; (3) Task Orientation; (4) Verbal Facility; and (5) Response to the Unfamiliar. The first three of these were found to be empirically similar to the three dimensions of the Classroom Behavior Inventory. These three factors plus the fourth, Verbal Facility, appeared to be conceptually similar to factors isolated in a number of other research-based social competency scales.

According to its authors, the California Preschool Social Competency Scale "was designed to measure the adequacy of preschool children's interpersonal behavior and the degree to which they assume social responsibility. Implicit in this definition is the concept of independence" (Levine, Elzey, \& Lewis, 1969, p. 1). The items were selected primarily on the basis of the judgment of early childhood educators and preschool personnel that the behaviors represented were important to the preschool child's social competency development. In the view of O'Malley (1977), such instrumentation is not associated with a background of research and was

APPLIED PSYCHOLOGICAL MEASUREMENT Vol. 4, No. 2 Spring 1980 pp. 203-212

(C) Copyright 1980 West Publishing Co. therefore excluded from his recent review of research on social competence.

Proger (1974), in a review of the California scale, complained that the construct validity of the scale had not been adequately investigated. He hypothesized four factors as forming the structure of the scale, namely, Work Habits, Personality, Communication, and Interpersonal Relations.

There are additional clues regarding the structure of the scale in the literature on social competency. Several authors (Baumrind \& Black, 1967; Becker \& Krug, 1964; Behar \& Stringfield, 1974; Kohn \& Rosman, 1972a; Lorr \& McNair, 1965; O'Malley, 1977; Peterson, 1960, 1965; Schaefer, 1975) have shown that much of the research on ratings of personality in general, and ratings of the social competence of preschool children in particular, can be integrated by a circumplex model in which the two major bipolar axes represent dimensions that can generally be labeled (1) Extraversion/Introversion and (2) Love/Hostility.

Schaefer (1975), in developing the Classroom Behavior Inventory, found that a third dimension, which he called Task Orientation/Distractibility, was required for an adequate measurement of classroom behavior. Schaefer cited a number of studies that isolated factors similar to Task Orientation (Beller, 1959; Digman, 1972; Miller, 1972; Werderlin, 1966). In addition, Em- 
merich (1971) found that a bipolar dimension labeled Task Versus Person Orientation was useful to add to the two-dimensional circumplex model in describing preschool personal-social behaviors in groups composed of predominantly black lower class children. Behar and Stringfield (1974) also isolated a Hyperactive-Distractible dimension in behavior ratings of preschool children, a dimension which they noted to be similar to one found by Peterson (1961), but which he chose to ignore for theoretical reasons.

Other researchers have maintained that social competence should also include a component of verbal competence. Richards and McCandless (1972), for example, found it "profitable to regard the personality domain as including verbal intelligence rather than excluding it" (p. 45). Their study, besides producing factors similar to introversion and hostility, also isolated a factor they named Verbal Facility, which had high loadings from teacher ratings of verbal skills and from an objective measure of verbal intelligence (Peabody Picture Vocabulary Test). That this factor was also related to a measure of peer acceptance (Picture Sociometric Technique) was deemed consistent with Dunnington's (1957) conclusion that verbal interaction is a major component of social acceptance among nursery school children. Moreover, Thompson (1962) made the case that social acceptance among children is dependent on factors similar to the dimensions of the circumplex model for social competence. In this light it would seem reasonable to view Verbal Facility as a possible fourth dimension of children's social competence.

The purpose of the present study was to investigate through factor analysis the dimensionality or underlying structure of the California scale as it is used with disadvantaged children. Schaefer's (1975) Classroom Behavior Inventory was also factor analyzed so that factor structures based on the same group of children could be compared. The dimensionality of the California scale will be compared directly to that of the Classroom Behavior Inventory and indirectly and conceptually to the dimensionality of other instruments that have been developed based on structure of personality theory (O'Malley, 1977). Thus, it will be seen to what extent the California scale, an instrument developed on the basis of the judgment of practitioners, corresponds to instruments developed through empirical research. Additionally, these comparisons should provide some evidence concerning the construct validity of the California scale and may have "implications for more practical interpretation of scale results" (Proger, 1974, p. 394).

\section{Method}

\section{Subjects}

Subjects rated on the California scale were 1,723 children attending the New York State Experimental Prekindergarten Program in 53 school districts throughout New York State in the 1975-1976 school year. The group included 858 girls and 865 boys. The mean age of the children, at the time ratings were assigned on the California scale, was $\mathbf{5 9}$ months, with a range of 45 to 77 months. About $40 \%$ of the sample were black, $45 \%$ white, and $11 \%$ Hispanic. The median education of mothers and fathers was 11.7 years. Median family income was $\$ 6,049$. The group rated on the Classroom Behavior Inventory were the same group less 47 children, and the above characteristics were essentially identical.

\section{Measures of Behavior}

California Preschool Social Competency Scale. The 30 items of this scale "cover a wide range of behaviors, such as response to routine, response to the unfamiliar, following instructions, making explanations, sharing, helping others, initiating activities, giving direction to activities, reaction to frustration, and accepting limits.... Each item contains four descriptive statements which represent varying degrees of competency relative to the behavior measured by 
that item. The items require observations of actual performance rather than inferences about presumed abilities or capacities" (Levine, Elzey, \& Lewis, 1969, pp. 3-4). The scale was designed to be used by teachers, who are instructed to assign ratings based on the child's habitual or typical performance rather than on any devised test situation. The authors report interrater reliability coefficients of .75 to .86 .

Classroom Behavior Inventory. This is an 18item rating scale designed to measure three dimensions of a child's affective behavior in the classroom. Each item consists of a statement describing some aspect of classroom behavior. The rater is instructed to rate the child in relation to this statement on a 4-point scale ranging from 1 (Not at all like) to 4 (Very much like). The three dimensions measured are bipolar in nature. They were determined by factor analysis when the scale was developed and include (1) Task Orientation/Distractability; (2) Hostility/Considerateness; and (3) Extraversion/Introversion. Six items load on each dimension, three on each pole. The score for each dimension is derived by subtracting the combined score of the items loading on one pole from the combined score of the items loading on the other pole. This yields subtest scores which can range from -9 to +9 . The author reports median interrater reliability coefficients ranging from .42 for Introversion to .68 for Hostility (Schaefer, 1975).

\section{Procedure}

Children were rated by their teachers on both scales shortly after entry into the program in September and again toward the end of the school year in May. For purposes of this analysis, only the latter posttest ratings were used. The teachers were given only minimal training in the use of the scales. Cases with missing data on any item were discarded. Principal components analysis was performed on the California posttest item scores, on the Classroom posttest item scores, and on the combined set of California and Classroom posttest item scores.
Components analysis was used as a good approximation to common factor analysis because it was desired to compute factor scores directly rather than to estimate them. The number of factors retained in each analysis was based on the scree test, or analysis of root plots (Cattell, 1966). The number of factors also happened to coincide in each analysis with the number of factors with eigenvalues greater than 1.0. Varimax rotation was used to provide a cleaner factor structure. An oblique rotation (direct oblimin) was also performed to determine if the factor structure was stable and to determine the correlation among factors. Interpretation of factors was based on an inspection of the content of the items loading on each factor.

Factor scores were calculated based on the orthogonal varimax factors. Correlations were then obtained for these scores across the two rating instruments as evidence of the correspondence of factors. In conformity with the research objective to compare the dimensionality of the California scale with the dimensionality of the Classroom scale, the orthogonal varimax solution was preferred rather than the oblique. This helped obtain a clearly interpretable correlation of factors from one scale with the factors of the other. Correlations between the factors of the scale could not be attributed to variance shared with other factors. In any case the two methods of rotation produced quite similar loading patterns, leading to essentially the same conclusions about the factor structures. Indeed, Nunnally (1967, chap. 9) has pointed out that numerous demonstrations have shown that the two approaches produce essentially the same results. Since this is so, and since the orthogonal solution produces factors which are mathematically simpler and which maintain desirable properties of the unrotated factors (e.g., the orthogonally rotated factors explained the same amount of variance as the unrotated factors), the orthogonal solution was also selected as the basis for presenting factor loadings. The oblique solution was used only to obtain some indication of the patterns of factor intercorrelation. 


\section{Results}

\section{Factor Analysis of the Califomia Scale}

The results of the California analysis are shown in Table 1. Five factors were rotated. The items with the highest loadings on each factor are shown with their respective loadings. The item numbers and labels are those used on the rating sheet itself; the verbal descriptions of factors were based on the content of the items loading on each factor.

Factor I was determined by items that have to

Table 1

Principal Components Analysis of

California Preschool Social Competency Scale Posttest Item Scores Varimax Rotated Factor Matrix

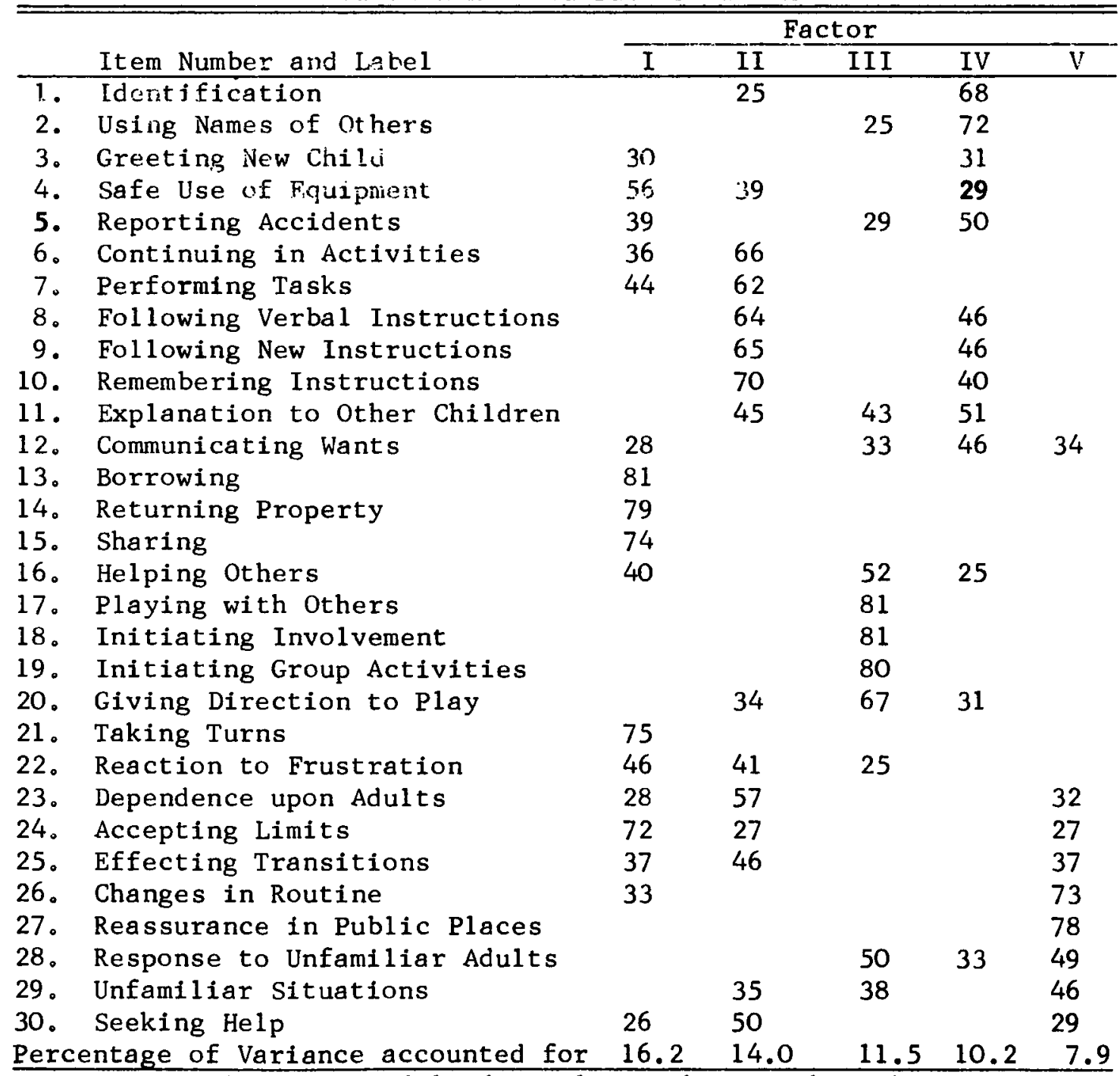

Note. Decimal points and loadings lower than .25 have been eliminated. 
do with borrowing, returning property, taking turns, sharing, accepting limits, and so forth. Low scores on these items are indicative of what might be considered hostile behavior ("takes objects when in use by others without asking permission," "seldom attempts to return the property to its owner," "interrupts or pushes others to get ahead of them in an activity taking turns," "does not share equipment or toys," "hardly ever accepts limits"). High scores on this factor would reflect a child who "nearly always asks permission to use others' objects," "nearly always returns the property to its owner," "waits for turn or waits to be called on," "frequently shares willingly with other children," and "nearly always accepts limits set by an adult." The factor was labeled Considerateness. It is similar conceptually to Peterson's (1960) General Adjustment, Digman's (1963) Successful Socialization, Schaefer's (1975) Considerateness Versus Hostility, and antonymous to Behar and Stringfield's (1974) Hostile-Aggressive dimension. It appears to be yet another replication of the Love Versus Hostility dimension of the circumplex model for rated behavior. This factor, of course, being unipolar, represents only one pole of that axis.

High scores on Factor II would be indicative of a child who "performs the activity without requiring repetition of instructions," "continues in his [or her] own activity in spite of interruptions," "can follow several verbal instructions at a time without a demonstration," "begins a task first time he [or she] is asked and is prompt in completing task," and "nearly always will continue in an activity on his [or her] own without having an adult participate with him [or her] or encourage him [or her]." This factor was designated Task Orientation. It is conceptually the unipolar equivalent of Schaefer's Task Orientation Versus Distractibility dimension.

The items which had the highest loadings on Factor III have to do with playing with others, initiating involvement, initiating group activities, giving direction to play, helping others, and responding to unfamiliar adults. High scores on this factor would be achieved by chil- dren who are active, involved, and outgoing; low scores would indicate children who hang back, take a passive stance, and avoid involvement with others. The factor appears to be clearly a unipolar analogue of the often-replicated Extraversion Versus Introversion dimension of the circumplex model.

Factor IV represents behavior that entails verbal competence and a readiness to use that competence. The highest loading items have to do with verbal expressiveness, i.e., using the names of others; identifying oneself by name, age, and address; making explanations to other children; reporting accidents; and verbally communicating wants. The three items concerning following and remembering instructions also have moderately high loadings on this factor, so that there would appear to be some verbal cognition involved as well. The factor was therefore labeled simply Verbal Facility. This factor is similar to a like-named factor isolated by Richards and McCandless (1972), with the notable exception that the verbal cognition variable loading highly on their factor was the Peabody Picture Vocabulary Test, an objective measure of verbal intelligence, rather than ratings of verbal comprehension, which was the case here.

Factor $\mathrm{V}$ accounted for the least amount of variance in the item set $(7.9 \%)$. It depended chiefly on items concerning unfamiliar or changing situations. A child scoring high on this factor would be rated as exhibiting adaptability, confidence, and equanimity in the face of such situations ("hardly ever needs reassurance when taken to public places," "nearly always accepts change in routine without resistance or becoming upset," "readily moves toward unfamiliar adults," "engages in an activity which is new for him [or her] even though other children are not involved"). The factor was designated Response to the Unfamiliar.

\section{Factor Analysis of Classroom Behavior Inventory}

The results of the factor analysis of the 18 items of the Classroom Behavior Inventory are items of the Classroom Behavior Inven
University of Minnesota, http://purl.umn.edu/93227. May be reproduced with no cost by students and faculty for academic use. Non-academic reproduction requires payment of royalties through the Copyright Clearance Center, http://www.copyright.com/ 
shown in Table 2. This factor-loading matrix essentially replicated the results obtained by Schaefer (1975) from 564 subjects in grades K-6. This replication, despite the difference in age groups, indicates a marked stability in the factor structure of this scale, especially since the raters were a diverse, relatively untrained group of observers. The three bipolar factors which the scale was designed to measure are readily apparent in the rotated factor matrix, Factor I being Task Orientation/Distractibility, Factor II Hostility/Considerateness, and Factor III Introversion/Extraversion.

\section{Congruence Across Measures}

A principal components analysis was also performed on the combined set of items from both the California and Classroom scales. Six factors were rotated and labeled: (1) Hostility/Considerateness; (2) Task-Orientation/Distractibility; (3) Verbal Facility; (4) Extraversion/Introversion-A; (5) Extraversion/Introversion-B; and (6) Response to the Unfamiliar. The five factors isolated above were repeated here with the same pattern of factor loadings. The Extraversion factor, however, was here split into two factors: The " $A$ " factor had moderate loadings from the California scale and heavy loadings from the Classroom scale; and the " $B$ " factor had moderate loadings from only two of the six Classroom items and moderate to heavy loadings from the California scale.

To further explore congruence, two sets of factor scores were computed from the separate orthogonal factors of each of the two scales.

Table 2

Principal Components Analysis of Classroom Behavior Inventory Posttest Item Scores Varimax Rotation

\begin{tabular}{lcccc}
\hline \hline & & \multicolumn{3}{c}{ Factor } \\
\cline { 3 - 5 } & Item No. & I & II & III \\
\hline Hostility & 5 & -14 & 83 & -02 \\
& 11 & -10 & 82 & -02 \\
Considerateness & 16 & -14 & 81 & 00 \\
& 6 & 46 & -62 & 06 \\
Task-orientation & 13 & 22 & -75 & -02 \\
& 15 & 28 & -65 & 06 \\
Distractibility & 2 & 82 & -15 & -09 \\
& 10 & 78 & -22 & -13 \\
& 18 & 82 & -17 & -09 \\
Extraversion & 4 & -79 & 22 & 04 \\
& 9 & -68 & 37 & 01 \\
Introversion & 14 & -79 & 08 & 22 \\
& 1 & -01 & -15 & -79 \\
Percentage of variance & 8 & 28 & 23 & -73 \\
accounted for & 12 & 03 & 15 & -76 \\
& 3 & -13 & -17 & 74 \\
& 7 & 02 & 14 & 83 \\
\end{tabular}


Pearson product-moment correlation coefficients were then calculated for the relationship between the California factor scores and the Classroom factor scores (Table 3).

The correlations between theoretically related dimensions were moderately high $(-.62, .64$, and -.58 ), thus confirming the general correspondence of these three factors across the two rating scales.

\section{Intercorrelation of Factors Within Scales}

Although orthogonal rotations were used to compute factor scores and study correspondence between the California and Classroom scales, oblique rotations were used here to provide some indication as to the intercorrelation of factors within each scale and to compare the pattern of factor intercorrelation in one scale with that in the other. Oblique rotations of both the California and Classroom factors produced the same factors as reported above in quite similar factorloading patterns.

The intercorrelations of the three factors that were common to both scales are shown in Table 4. The pattern of intercorrelation was similar for the two scales, with a close relationship between Considerateness/Hostility and Task Orientation, a lesser relationship between Extraversion and Task Orientation, and little or no relationship between Considerateness/Hostility and Extraversion. The intercorrelations shown here for the Classroom scale are very close to those reported by Schaefer (1975) on data collected in 1972 and 1974. The same pattern of intercorrelation for factors similar to these three has been reported by Kohn and Rosman (1972a) and by Behar and Stringfield (1974).

The Verbal Facility factor correlated highest with Extraversion (.38), less with Task Orientation (.27), and least with Considerateness (.01). The same pattern emerged when California factor scores (computed from orthogonal factors) were correlated with Classroom factor scores (Table 3). To the extent that the Verbal Facility factor is a cognitive factor, this relationship pattern substantiates similar findings by Kohn and Rosman (1973) and by Richards and McCandless (1972). To the extent that it is a verbal expressiveness factor, these correlations also support the findings of Kohn and Rosman (1973).

The Response to the Unfamiliar factor correlated highest with Extraversion, which is consistent with Table 3. However, the almost equally high correlation with Task Orientation is not consistent with Table 3.

\section{Discussion}

The factors found here to comprise the structure of the California scale came close to coinciding conceptually with the four factors hypothesized by Proger (1974). Proger specified items from the scale that he believed would con-

Table 3

Intercorrelations of Factor Scores from

California Preschool Social Competency Scale and

Classroom Behavior Inventory

\begin{tabular}{|c|c|c|c|c|c|}
\hline \multirow[b]{2}{*}{$\begin{array}{l}\text { Classroom } \\
\text { Behavior } \\
\text { Inventory }\end{array}$} & \multicolumn{5}{|c|}{ California Preschool Scale } \\
\hline & $\begin{array}{l}\text { Consider- } \\
\text { ateness }\end{array}$ & $\begin{array}{c}\text { Task } \\
\text { Orientation }\end{array}$ & $\begin{array}{l}\text { Extra- } \\
\text { version }\end{array}$ & $\begin{array}{c}\text { Verbal } \\
\text { Facility }\end{array}$ & $\begin{array}{c}\text { Response } \\
\text { to } \\
\text { Unfamiliar }\end{array}$ \\
\hline $\begin{array}{c}\text { Hostility } \\
\text { Task }\end{array}$ & -.62 & .04 & .10 & .13 & -.11 \\
\hline Orientation & .31 & .64 & .04 & .21 & .04 \\
\hline Introversion & .05 & -.01 & -.58 & -.25 & -.25 \\
\hline
\end{tabular}


Table 4

Intercorrelations of Factors after Oblique Rotation

\begin{tabular}{lcccc}
\hline \hline & $\begin{array}{c}\text { Task } \\
\text { Orientation }\end{array}$ & Extraversion & $\begin{array}{c}\text { Verbal } \\
\text { Facility }\end{array}$ & $\begin{array}{c}\text { Response to } \\
\text { Unfamiliar }\end{array}$ \\
\hline & & California & Preschool Scale & \\
\hline Considerateness & .65 & .35 & .01 & .46 \\
Task Orientation & & .55 & .27 & .53 \\
Extraversion & & & .38 & .56 \\
Verbal Facility & & & & .14 \\
\hline
\end{tabular}

Classroom Behavior Inventory

Hostility $-. .51 \quad-.02$

Task Orientation .31

stitute each factor. His hypothesized Work Habits factor corresponds closely with the Task Orientation factor from the current study and his Communication factor corresponds with Verbal Facility. The items he surmised would form a Personality factor (perhaps too broad a term) actually fell out more precisely on three factors: Considerateness, Task Orientation, and Response to the Unfamiliar. Proger's fourth factor, Interpersonal Relations, also split more precisely into two factors here, namely, Considerateness and Extraversion.

Two of the California factors, Considerateness and Extraversion, have a conceptual correspondence with the two dimensions of the circumplex model for child behavior. These two factors, along with the Task Orientation factor, coincided conceptually not only with the three factors of Schaefer's Classroom Behavior Inventory but also with similar constructs that recur throughout the literature on children's social-emotional behavior (Behar \& Stringfield, 1974; Kohn \& Rosman, 1973; Schaefer, 1975). In addition, the correlations of factors across instruments (high correlations between theoretically related dimensions and low correlations between theoretically unrelated dimensions) and the similar patterns of intercorrelation among oblique factors within instruments provide some empirical evidence for the correspondence of the California factors and the Classroom factors. Schaefer's Classroom factors likewise have been empirically shown to have congruence with Peterson's dimensions of personality and conduct problems (Kohn \& Rosman, 1972a).

The California scale clearly contains a fourth factor, which Proger suggested might be a Communication factor and which can be designated Verbal Facility. The content of the items loading on this factor indicate that there are elements of both verbal comprehension and verbal expressiveness involved. This dimension has not often been reported in the literature as having been sampled in instruments purporting to measure children's social competency. Richards and McCandless (1972) do, however, report a similar factor in a study of socialization dimensions among slum children; this factor correlates by an estimated .63 with a factor similar to the California Extraversion factor.

Finally, a weak fifth factor, designated Response to the Unfamiliar, was also isolated. This factor does not appear to replicate any other major dimension found elsewhere.

The relationship among the dimensions found here was observed in two ways: (1) by computing factor scores from the orthogonal principal components of the two scales and by observing the correlations of factor scores across instruments and (2) by performing an oblique rotation of factors within each of the two instruments and examining the intercorrelations of factors. The pattern that emerged is substantially in agreement with other reported findings regarding the 
relationship of social-emotional dimensions similar to these (Behar \& Stringfield, 1974; Kohn \& Rosman, 1972a, 1972b, 1973; Richards \& McCandless, 1972; Schaefer, 1975). In this pattern Considerateness/Hostility and Task Orientation/Distractibility are related to some degree, with Extraversion/Introversion tending to be more independent. But when the relationship of these three dimensions with a verbal or other cognitive dimension is observed, it was found that Extraversion/Introversion and Task Orientation/Distractibility were substantially related to the cognitive dimension but that Considerateness/Hostility was not. This suggests that children who are considerate, well adjusted, and loving tend also to be able to concentrate and become absorbed in activities. There is also some tendency for children who are thus task oriented, and also for children who are extraverted, to achieve more in the way of cognitive functioning; but whether children are hostile and defiant or considerate and compliant seems to have little to do with their cognitive functioning, at least at the preschool level.

The California Social Competency Scale was developed in a clinical way without (as O'Malley, 1977 , notes) being associated with a background of research. It appears, however, that regardless of how it was developed, the structure of the scale is in concordance with the structure of other instruments that were developed based on a background of research and that purport to measure essentially the same constructs. The structure integrates well in the nomological network on child behavior and social competency.

Knowing the factor structure of the California scale also has implications for its interpretation and use. As far as using the scale to produce social competency profiles for diagnostic purposes, it would not be a simple matter of summing up the scores on specified items to produce approximate factor scores. This is because many of the items are factorially complex; they load on more than one factor. In order to get a factor profile, actual factor scores would have to be computed. The feasibility of the procedure is uncertain. In any case, the reliability of the factor structure would have to be determined. Perhaps a more productive and feasible use of factor scores such as were produced here would be in the evaluation of preschool programs. As measures of the effectiveness of such programs in fostering development in social competency, the factor scores would certainly be more meaningful and more reliable than a single global score.

\section{References}

Baumrind, D., \& Black, A. E. Socialization practices associated with dimensions of competence in preschool boys and girls. Child Development, 1967, 38, 291-327.

Becker, W. C., \& Krug, R. S. A circumplex model for social behavior in children. Child Development. 1964, 35, 371-396.

Behar, L., \& Stringfield, S. A behavior rating scale for the preschool child. Developmental Psychology, 1974, 10, 601-610.

Beller, E. K. Exploratory studies of dependency. Transactions of the New York Academy of Science, 1959, Sec. 2, 21, 414-426.

Cattell, R. B. The scree test for the number of factors. Multivariate Behavioral Research, 1966, 1, 245275.

Digman, J. M. Principal dimensions of child personality as inferred from teachers' judgements. Child Development, 1963, 34, 46-60.

Digman, J. M. High school academic achievement as seen in the context of a longitudinal study of personality. Proceedings of the 80th Annual Convention of the American Psychological Association. 1972, 7, 19-20.

Dunnington, M. Behavior differences of sociometric status groups in a nursery school. Child Development, 1957, 28, 103-111.

Emmerich, W. Structure and development of personal-social behaviors in preschool settings. Princeton, NJ: Educational Testing Service, 1971.

Kohn, M., \& Rosman, B. L. A social competence scale and symptom checklist for the preschool child. Developmental Psychology, 1972, 6. 430-444. (a)

Kohn, M., \& Rosman, B. L. Relationship of preschool social-emotional functioning to later intellectual achievement. Developmental Psychology. 1972, 6, 445-452. (b)

Kohn, M., \& Rosman, B. L. Cognitive functioning in five-year-old boys as related to social-emotional and background-demographic variables. Developmental Psychology, 1973, 8, 277-294. 
Levine, S., Elzey, F. F., \& Lewis, M. Manual: California Preschool Social Competency Scale. Palo Alto, CA: Consulting Psychologists Press, 1969.

Lorr, M., \& McNair, D. M. Expansion of the interpersonal behavior circle. Journal of Personality and Social Psychology, 1965, 2, 823-830.

Miller, L. C. School behavior checklist: An inventory of deviant behavior for elementary school children. Journal of Consulting and Clinical Psychology, 1972, 38, 134-144.

Nunnally, J. C. Psychometric theory. New York: McGraw-Hill, 1967.

O'Malley, J. M. Research perspective on social competence. Merrill-Palmer Quarterly, 1977, 23, 30-44.

Peterson, D. R. The age generality of personality factors derived from ratings. Educational and Psychological Measurement, 1960, 20, 461-474.

Peterson, D. R. Behavior problems of middle childhood. Journal of Consulting Psychology, 1961, 25. 205-209.

Peterson, D. R. Scope and generality of verbally defined personality factors. Psychological Review, $1965,72,48-59$.

Proger, B. B. Test Review No. 17: California Preschool Social Competency Scale. Journal of Special Education, 1974, 8, 391-395.
Richards, H. C. \& McCandless, B. R. Socialization dimensions among five-year-old slum children. Journal of Educational Psychology, 1972, 63, 44-45.

Schaefer, E. S. Major replicated dimensions of adjustment and achievement: Cross-cultural, crosssectional, and longitudinal research. In J. M. O'Malley (Chair), Dimensions of competence in classrooms. Symposium presented at the annual meeting of the American Educational Research Association, Washington, DC, April 1975.

Thompson, G. G. Child Psychology. Boston: Houghton Mifflin, 1962.

Werderlin, I. Teacher ratings, peer ratings, and self ratings of behavior in school (Bulletin No. 11). Malmo, Sweden: School of Education, Department of Education and Psychological Research, March 1966.

\section{Author's Address}

Send requests for reprints or further information to David L. Flint, Prekindergarten Evaluation Unit, Room 367 EBA, New York State Education Department, Albany, NY 12234. 